\title{
Bogotá, urbanismo posmoderno y la transformación de la ciudad contemporánea ${ }^{1}$
}

\author{
Jhon Williams Montoya²
}

\begin{abstract}
RESUMEN
Señala con acierto Pierre Carrière que los geógrafos humanos admiten la ideología como una de las variables que, al mismo nivel que el medio natural, la cultura y la historia, definen la configuración física y social de la sociedad. En este escrito se explora la relación entre ideología y urbanización para el caso de Bogotá después de 1990. La tesis central es que los años noventa evidenciaron la emergencia y dominancia de un ideal urbano posmoderno, basado en la planificación comunicacional, el cual definió las políticas urbanas de las dos últimas décadas. El documento analiza la crisis de la planificación racional moderna, la consolidación del Ilamado Modelo Barcelona y su implementación en la política urbana de Bogotá. Las conclusiones se orientan al examen de la relación entre planificación comunicacional y posmoderna, globalización y la nueva morfología urbana de la ciudad.
\end{abstract}

Palabras clave: Utopías urbanas, planificación urbana, ordenamiento territorial, morfología urbana, urbanismo.

\begin{abstract}
Pierre Carrière notes that human geographers acknowledge that ideology is a very important variable that, to same extent as culture, history or nature, defines the physical and social organization of society. This paper explores the relationship between ideology, urbanism and urban change in Bogotá after 1990. The central thesis is that during the nineties a postmodern discourse on the communicational planning arose in Bogotá; this discourse then dominated urban politics over the last 2 decades. This paper analyzes the modern rational planning crisis, the arrival of the Barcelona Model and its implementation on the urban politics of Bogotá. The conclusions are aimed toward examining the relationship between the postmodern and communicational planning, the globalization process and the new urban morphology of Bogotá.
\end{abstract}

Key words: Urban utopia, urban planning, zoning, urban morphology, urbanism.

\footnotetext{
1 Este artículo es derivado de la Tesis "Bogotá: Crecimiento urbano y cambio morfológico, 1538-2010", presentada en el Doctorado en Ciencias Geográficas, Université Laval. Fue elaborado bajo la dirección del Profesor Guy Mercier, de la Université Laval y con el apoyo del Departamento de Geografía de la Universidad Nacional de Colombia.
}

Artículo recibido el 14 de mayo de 2012, aceptado el 14 de mayo de 2013 y corregido el 11 de julio de 2013.

2 Departamento de Geografía, Universidad Nacional de Colombia (Colombia).

E-mail: jwmontoyag@gmail.com 
Para José Luis Romero, uno de los grandes avances en la lectura de los procesos históricos lo constituye la incorporación del estudio de las ideas y su relación con la transformación social; avance que ubica en la Ilustración y particularmente en la obra de Voltaire (Romero Peñas, 1987). Así, el estudio de las ideas, y por extensión de la ideología, constituye una variable fundamental en el análisis del cambio social, a través de las acciones de los grupos hegemónicos, aunque también de los otros grupos sociales, sujetos activos de la transformación material y desarrolladores de acciones fuertemente influenciadas por la ideología. Igualmente a nivel urbano, las mentalidades, como señala Romero, han tenido un papel significativo en el modelamiento físico y social de las ciudades. De hecho, ellas nacen de una diferenciación significativa de los estilos de vida, en particular aquellos de origen rural, antónimos de las formas de vida urbana. La ciudad está, pues, impregnada de ideologías, de cultura, de mentalidades y de utopías. Estas últimas han tenido una amplia participación en la construcción de los discursos sobre lo urbano y han moldeado, a través de la 'ciudad ideal' que proyectan, la política urbana y con ella la materialidad física y social de la ciudad.

Así, el estudio de los discursos urbanos puede partir inicialmente de un examen del papel de las utopías. A ese respecto, Françoise Choay (1996) establece siete condiciones fundamentales para definirlas. En ellas se especifica una secuencia que parte de un individuo que genera una narrativa en que se modela una sociedad ideal; este ideal es inmediatamente contrapuesto a una sociedad real que es, sin embargo, calificada como indeseable y catastrófica, si bien ella constituye la materia prima sobre la cual se ha de ejecutar la utopía. Efectivamente, la utopía se formula fuera del encuadre espacio-temporal actual, pero requiere un contexto espacial para su desarrollo, por lo que toma el espacio real como escenario sobre el cual intervenir.

De lo anterior se colige que la utopía es una narrativa positiva que proyecta un ideal sobre un escenario, y en consecuencia un espacio, real y contemporáneo. Así, la utopía se formula siempre en contra de la ciudad real a la que critica, desconoce y pretende transformar. Además, parte necesariamente de una insatisfacción con el discurso o la utopía existente y precedente, sea por obsolescencia o por inadecuación a las condiciones actuales. No sobra decir, también, que el destino final de toda utopía es verse sujeta a esta crítica, pues cuando un ideal se hace dominante, las realizaciones siempre serán insatisfactorias y un nuevo ideal surgirá desde la oposición. De esta manera, como señala Mannhein (2003 [1929]), el triunfo de la utopía constituye su perdición, pues se diluye al imponerse y se hace incapaz de significar una renovación; se convierte entonces en el statu quo y en el objetivo de ataque por parte de las utopías emergentes.

Estas ideas conducen a formular un objetivo para este escrito, el de ilustrar la transición de Bogotá de una planificación racional y moderna, a un nuevo discurso inspirado en el modelo Barcelona y principios del urbanismo posmoderno. En resumen, el artículo se desarrolla en función de dos propósitos: elaborar un diagnóstico de los principales elementos que alimentan la narrativa posmoderna y en particular su derivación en el Modelo BarceIona; y evaluar cómo se incorporaron estos elementos en las prácticas planificadoras de Bogotá a partir de la literatura de planificación, en especial aquella asociada con el pensamiento urbano de Antanas Mockus y Enrique Peñalosa. Los principales documentos corresponden al Acuerdo 6 de 1990, la Ley 388 de 1997, el Plan Estratégico para Bogotá (2000) y el Plan de Ordenamiento territorial para Bogotá (2000).

\section{De la planificación racional moderna a la planificación comunicativa}

La evolución histórica de la planificación en Colombia y Bogotá (ver Figura $N^{\circ} 1$ para su localización), han estado estrechamente ligadas al contexto internacional y en particular a las transformaciones ideológicas que han tenido, a nivel planetario, los discursos de la planificación urbana y regional. Las décadas de los noventa y dos mil no son diferentes, a pesar del esfuerzo de los promotores del 'milagro bogotano' ${ }^{3}$ por tratar de mostrar

3 Reivindicado frecuentemente tanto por políticos e intelectuales afines a los dos alcaldes más notorios de las últimas décadas: Antanas Mockus y Enrique 
los cambios en la gestión de la ciudad como una revolución esencialmente local.

En ese sentido, la planificación en general y la planeación urbana en Bogotá experimentaron, desde los años sesenta, significativas transformaciones. Estos cambios comenzaron con un ataque y debilitamiento importante de la planificación moderna, incluyendo la planificación comprensiva-integral, la cual constituyó, para muchos autores, la adaptación del modernismo al nuevo contexto sociopolítico. Así, la verdadera transición, tanto en la teoría como en la práctica de la planificación, tendría lugar solamente a finales de la década de los años ochenta con la crisis de la planificación estatal, considerado el último baluarte del modernismo, y la emergencia de la planificación comunicacional o colaborativa (Allmendinger y Tewdwr-Jones, 2002; Fainstein, 2000; Hamel, 1997; Healey, 1996; Taylor, 1998).

Como consecuencia de estos eventos se concluye que la crítica al urbanismo moderno se asocia con un amplio desarrollo de los discursos posmodernos, incluyendo el cuestionamiento profundo al proyecto ilustrado y en particular al racionalismo científico, además de la creciente conciencia de una transformación radical de la sociedad y en particular de la sociedad urbana (Bédard, 2000; Dear y Flusty, 1998; Hamel, 1997). El cambio en todos los órdenes que ha experimentado la sociedad contemporánea, hace el proceso reciente de transformación social comparable a lo que en su momento permitió a Le Corbusier concebir la idea de la sociedad maquinista, situación que muestra como la planificación contemporánea también acude al mito del surgimiento de una Nueva sociedad (Castells, 1996), y propone igualmente un 'rompimiento radical de la urbanización' (Beauregard, 2006), poniendo en cuestión la teoría urbana existente y leyendo la planificación actual como inoperante y necesariamente revaluable. En ese sentido, Friedmann identifica, para la época reciente, un cambio histórico acelerado que contrasta con la exigencia de perennidad de la planificación tradicional, determinando entonces una rápida

Peñalosa (p. ej. Bromberg, 2003; Montezuma, 2005); como por planificadores adherentes al Nuevo Urbanismo (p. ej. Gehl, 2004). obsolescencia de los planes, acompañado de nuevos retos para la sociedad contemporánea, especialmente de orden ambiental y de rápida urbanización que, con un Estado en retroceso, son imposibles de satisfacer por la planificación tradicional (Friedmann, 1987).

Figura $\mathrm{N}^{\circ} 1$

Localización de Colombia y Bogotá en el extremo noroccidental de Suramérica

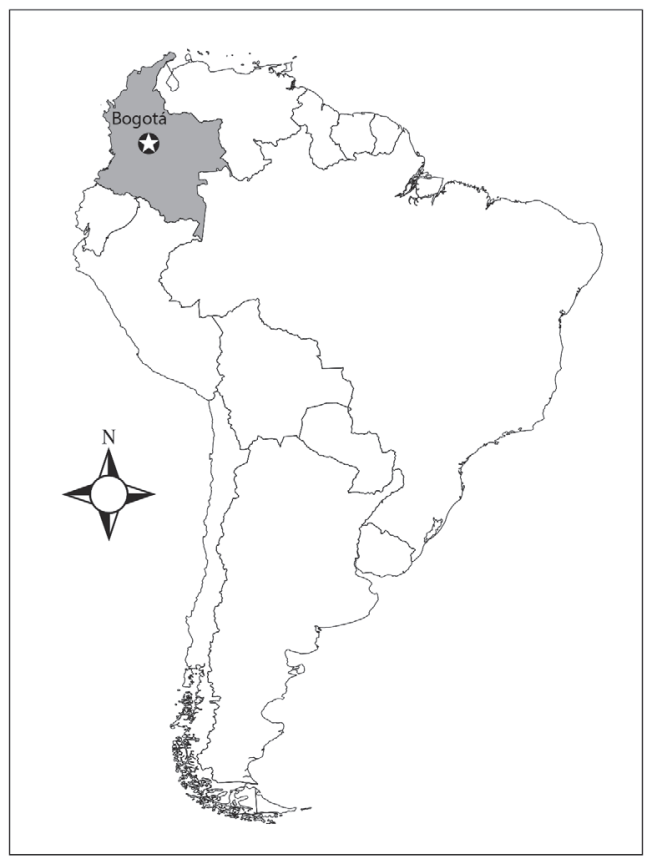

Fuente: Elaboración propia.

Este cambio social y su proyección a la planificación, también se reconoce en una desilusión generalizada con el proyecto moderno, representado en la planificación racional. El listado de agravios frente a ella es amplio e incluye la crítica a su cooptación por el capital, situación propia de una planificación que desde los años setenta se había estado moviendo hacia el marketing cívico y a la formulación de políticas de empresarialismo urbano, claves en la transición de régimen fordista a uno posfordista (Harvey, 1989). En ese sentido, la acción del Estado, informada por la planificación, se hizo evidentemente incapaz de resolver los problemas básicos de la población, con un divorcio total entre conocimiento y acción (Friedmann, 1987). Ello derivaba, a su vez, del carácter excesivamente abstracto de la planificación racional y la no consideración del conflicto político 
como un elemento central de las decisiones, ignorando las características de los agentes urbanos e indiferente a la dinámica del ambiente construido (Beauregard cit. por Fainstein, 2000).

En concordancia con los elementos anteriormente citados, es necesario considerar también que la Planificación racional tuvo una derivación física que se concentró en la renovación urbana, el desarrollo en baja densidad y una segregación espacial y funcional cada vez más intensa (Fainstein, 2000). Esta situación condujo a una ciudad múltiple y fragmentada en extensas áreas metropolitanas, poco correspondientes a la idea de ciudad compacta y unitaria que ella preconizaba.

En suma, si bien en su momento la planificación racional constituyó una alternativa a la crisis del Alto modernismo, también heredó, en la perspectiva de sus críticos, la mayor parte de sus males: autoritarismo, objetivismo, búsqueda del control. A lo anterior se añadía también un fuerte utilitarismo derivado de la urgencia por la acción y la fatiga frente a la teorización que muchos planificadores encontraban inútil y abstrusa. Esta situación se combinaba con cierto antiintelectualismo propio del pragmatismo exigido por el involucramiento en la resolución de problemas concretos e inmediatos, pero también la emergencia de un capitalismo tardío, equiparado con una ciudad posmoderna, que hacía obsoleta la planificación moderna ya que el Estado, y por extensión la planificación, no pueden cumplir la función de mediadores, al ser cada vez más rehenes de las demandas del capital.

De este contraste con la planificación racional emerge, en los años noventa, la planificación comunicacional ${ }^{4}$, como teoría dominante en planificación urbana, basada principalmente en lo que Healey Ilamó un 'Communicative turn' (en Harris, 2002), incorporando varias corrientes y estrategias que tienen como soporte la teoría comunicacional de Jurgen Habermas. Habermas parte de

\footnotetext{
4 Denominada planificación colaborativa en Gran Bretaña (Allmendinger \& Tewdwr-Jones, 2002).
}

la reafirmación del lenguaje no solo como una representación genuina, e imperfecta, del mundo, sino también como un mecanismo a través del cual, con la comunicación y la discusión, se arriba a consensos democráticos próximos a la verdad reivindicada por el racionalismo (Cooke, 1990). El lenguaje, según Habermas, "...es capaz de darnos las herramientas para dar forma a una teoría de la razón nueva y mejor" (Healy, 1996: 338). Así, para Healey, Habermas reformula el concepto moderno de razón y permite cambiar de un conocimiento derivado de una relación sujeto-objeto, a un razonamiento formado dentro de una comunicación intersubjetiva, que a su vez es contextual y situada. Como consecuencia, dos elementos aparecen con un rol protagónico en la planificación: la acción y la subjetividad humana (Healey, 1996).

Igualmente, la planificación comunicacional promueve el paso de una planificación indicativa a una nueva forma construida alrededor del debate que supone la existencia de 'comunidades discursivas', con las cuales se construye el conocimiento necesario para la acción a través de 'la discusión respetuosa' (Healy, 1996: 247). Esta nueva planificación constituye, entonces, un proceso interactivo que remite a una acción del Gobierno en un ambiente complejo donde intervienen múltiples actores, y en la que se tiene el propósito de cualificar espacios y territorios. Allí la planificación ambiental alcanza un importante rol, y además, la planificación toda se soporta en un fundamento estético y moral, en particular reivindicativo de la justicia social en la ciudad, pero orientado más allá de las disputas materiales, hacia asuntos de género y raza y colocando las cuestiones culturales en una posición prominente (Harris, 2002; Healey, 1996; Healey, 2003; Sandercock, 1998).

La planificación comunicacional se sustenta, entonces, en principios que la hacen sustantivamente distinta a la planificación moderna y racional. El primero de ellos es su inspiración en cierto 'socialismo democráti$\mathrm{CO}^{\prime}$, reivindicando su apego a una versión de democracia distinta a la impuesta por la tradición liberal del siglo XX, y que tiene como apoyo los movimientos sociales. Friedmann resume esta faceta de la Nueva planificación en el reposicionamiento general de la idea de sociedad civil, rechazando la interpretación 
liberal de ella y reivindicándola más bien como consecuencia de la naturaleza gregaria y comunicacional del ser humano, opuesta no solo al Estado, sino también a la economía corporativa que la amenaza constantemente (Friedmann, 1987; Friedmann, 1998). El retorno a este nivel básico de organización conlleva, por otra parte, a la reivindicación del comunitarismo como fuente de legitimación de la acción planificadora, basada en la comunicación y la participación. El planificador pierde entonces su posición de intérprete y científico constructor de la utopía urbana, convirtiéndose en un comunicador encargado de facilitar el intercambio entre los diferentes agentes. Como consecuencia, la planificación se fragmenta y pierde su carácter totalizante, para refugiarse en el nivel micro y local.

Finalmente, este conjunto de preceptos necesariamente conduce a una reformulación de las funciones y organización del Estado. Es lo que podría denominarse una Nueva gubernamentalidad, referida a la refundación de las relaciones políticas que reemplazarían el Estado de bienestar, buscando resolver las incoherencias de este último, especialmente su poca atención a la diferencia, a la comunidad y al lugar, incompatibles con un sistema centrado en los derechos sociales individuales; pero también ajustado a la nueva realidad de una economía capitalista globalizada (Marris, 1998). La Nueva gubernamentalidad implica, entonces, el empoderamiento de los diferentes grupos, marginalizados en la planificación racional, y con ello la constitución de gobiernos urbanos altamente descentralizados en los que las ONG adquieren un rol protagónico, influenciando la política en todas las escalas (ibid.), a la par del debilitamiento de las viejas formas de organización como los partidos y los sindicatos.

De esta manera el gobierno urbano entra en una etapa de gestión que Harvey (1989) denomina de 'empresarialismo urbano', estrechamente ligada al carácter estratégico que, en el nuevo orden capitalista, adquieren las principales áreas metropolitanas. La ciudad se convierte así, en esta narrativa planificadora, en un agente económico más susceptible de administrarse con principios equivalentes a los de las empresas y en el que es fundamental la asociación público-privada, elevada al rango de 'la mejor práctica' en gober- nancia urbana (Brenner \& Theodore, 2005). Esta asociación se caracteriza especialmente por la absorción del riesgo en los proyectos urbanos por el sector público y la concentración de los beneficios por el sector privado; también por una escala de acción centrada en el lugar (Harvey 1989) y la incorporación del sector privado en la toma de decisiones, a la vez que el Estado abraza formas empresariales de organización (Larsen y Hansen, 2008).

\section{El Modelo Barcelona}

La renovación de la planificación urbana a través de la Planificación comunicativa y otras variantes del urbanismo posmoderno se expandió rápidamente en los años noventa e invariablemente en todos los lugares dio lugar a positivas expresiones como el 'renacimiento de la ciudad', aplicado a Baltimore, o la 'ciudad reconquistada' en el caso de Barcelona. Esta última ciudad inició, desde los años ochenta, un intenso proceso de transformación, apalancado además por flujos importantes de capital derivados de la incorporación de España a la economía europea, una vez consolidada la transición a la democracia, y la existencia de un amplio déficit urbanístico y de renovación, resultado también del inmovilismo impuesto por la dictadura (Buchanan, 1990; Delgado, 2007). A ello se añadía una importante tradición planificadora, con lo que la ciudad desarrolló intensos procesos de reestructuración física y social que, soportados en la nueva gobernancia y varios de los elementos previamente reseñados, dieron lugar a una forma urbana emblemática de la urbanización contemporánea, impulsada especialmente a partir de la designación de la ciudad como sede de los Juegos Olímpicos en 1992.

Las estrategias planificadoras aplicadas en Barcelona fueron largamente divulgadas en América Latina y progresivamente se consolidó lo que se Ilamó el Modelo Barcelona5; un

\footnotetext{
5 La idea de modelo es fuertemente cuestionada tanto por sus detractores (Delgado, 2007), participantes (Bohigas, 1990) o 'arrepentidos' (Borja, 2005). En este caso mantendremos la idea del 'Modelo Barcelona' como un discurso urbanístico que se promovió como la mejor estrategia de planificación y fue
} 
conjunto de ideas, prácticas y estrategias que trascienden la intervención urbanística (concentrada esta en la defensa del espacio público) e incluyen elementos como el desarrollo económico de la ciudad, la descentralización municipal, la política fiscal, la cooperación Estado-empresa, la seguridad ciudadana y la movilidad urbana (Capel Sáez, 2005). Barcelona se convirtió así en el prototipo de la ciudad postindustrial e incluso es representada por muchos como el paradigma de la ciudad neoliberal (Delgado, 2007).

En función al objetivo propuesto, interesa entonces examinar los postulados fundamentales del Modelo Barcelona, para derivar luego su impacto en el urbanismo bogotano. En primera instancia habría que reafirmar que el discurso sobre el Modelo Barcelona se asimila a dos condiciones claramente definidas: en el plano ideológico, el modelo reivindica la tradición culturalista del urbanismo y en especial los discursos clásicos sobre la naturaleza de comunidad de la ciudad; mezclado con el individualismo a ultranza y el ataque al Estado de bienestar y centralizador, ambos elementos fundamentales de la narrativa neoliberal. En el plano de la gestión urbana, por otro lado, el modelo incorpora plenamente los discursos contemporáneos sobre ciudad global y sitúa la ciudad como protagonista de primer orden en la economía capitalista contemporánea. Esta afiliación irrestricta con la urbanización posfordista es matizada con la reivindicación de algunos elementos de la 'ciudad justa', aunque en un contexto posmoderno de exaltación de la diferencia y el convencimiento pleno del fracaso de las lecturas y modelos modernos, respecto a la desigualdad de la sociedad y de la ciudad.

Sobre el primer punto, es decir, la dimensión ideológica, es necesario retornar a la valorización de la ciudad clásica que tiene lugar en la década de los sesenta como reacción al modernismo. Esta reivindicación, también esgrimida por Borja y Bohigas, reclama la ciudad como espacio democrático por excelencia, en el que confluyen los diferentes grupos sociales, donde se debate y dialoga y

adoptado, con las correspondientes contextualizaciones, en la ciudad de Bogotá. que tiene intrínsecos un conjunto de valores: libertad, cohesión social, derechos, identidad y democracia participativa (Bohigas, 2004; Borja, 2005; Buchanan, 1990); en suma, la ciudad es el espacio de la comunalidad.

Una consecuencia inmediata de esta reivindicación de la ciudad clásica y sus formas es la mitificación del espacio público ${ }^{6}$, que se convierte en leitmotiv de la planificación y se califica como el escenario urbano por excelencia. Borja, basado en Habermas y en general en la tradición culturalista de la ciudad, señala que la 'ciudad es espacio público', puesto que en él convergen tanto los ciudadanos como los intercambios; pero también porque es en él donde se materializa el 'simbolismo colectivo' y en últimas la representación del poder (Borja, 2005).

El espacio público se justifica, entonces, como lugar de expresión ciudadana y ello conduce a un segundo elemento guía del urbanismo barcelonés, la formación ciudadana. Partiendo de la idea de ciudad como máxima expresión de la cultura y el ingenio humano, los promotores de este tipo de urbanismo consideran que la planificación no solamente debe proveer el espacio público para la interacción, sino también construir permanentemente la ciudadanía. En ese sentido, el urbanismo, y especialmente a través de la promoción del espacio público, habría de orientar su acción a la adopción de unos patrones de comportamiento cívicos, bajo las premisa de que el ciudadano se hace y las formas transmiten valores y son por tanto un vehículo eficiente de educación (Borja, 2005).

Por otra parte, la sublimación del espacio público, equiparado a derecho ciudadano según Borja (2005: 184) y la idea de formación ciudadana, confluyen efectivamente

\footnotetext{
6 Es conveniente recalcar que el espacio público es una invención de los años setenta, consecuencia de la transformación del uso de los espacios colectivos resultado de la modernización, la masificación del automóvil y la suburbanización. Su conceptualización e inclusión como elemento central del urbanismo igualmente deriva de una lectura de crisis $y$ deterioro de la vida urbana y colectiva, percibida por un grupo importante de urbanistas en la década de los setenta (Fleury, 2008).
} 
en el marketing urbano; una estrategia publicitaria orientada a imponer una forma de 'patriotismo cívico' (Bohigas, 2004) que, aparte de promover una mayor participación ciudadana y un mayor compromiso con la ciudad, legitimó un 'culturalismo de mercado' y una mercantilización generalizada de los valores arquitectónicos y culturales de la ciudad (Fiori Arantes, 2000). Este 'patriotismo cívico', amalgamado a un capitalismo cultural desregulado, condujo a la legitimación e imposición de una sola forma de ver la ciudad, arrinconando las voces disidentes, legitimando no solo políticas económicas frecuentemente lesivas a importantes grupos urbanos, sino también la imposición de modelos de seguridad fuertes, que condujeron a la expulsión arbitraria de habitantes que obstaculizaban el 'ideal urbano'; en particular, en los casos de grandes proyectos de renovación urbana.

Un tercer elemento corresponde a la patrimonialización de la ciudad, derivada del peso que el urbanismo cultural otorga a la historia. Esta preocupación se tradujo en políticas agresivas no solo de conservación arquitectural (y también del patrimonio cultural), sino también de revalorización del Centro Histórico que terminaría, en Barcelona y muchas otras ciudades, con procesos agudos de gentrificación. La renovación urbana y la gentrificación asociada son, entonces, características particulares del Modelo Barcelona, aunque con una reivindicación patrimonial fuertemente condicionada por los intereses del capital inmobiliario. Efectivamente, Capel señala que las intervenciones arquitectónicas 'agresivas' contra el paisaje patrimonial son constantes en Barcelona y expresan una tensión constante entre un interés real por el patrimonio y una concepción mercantil del mismo, saldándose el conflicto frecuentemente a favor de los intereses del sector inmobiliario (2005).

Finalmente, y teniendo en cuenta que la imposición de la nueva narrativa requería crear la idea de la existencia de una profunda crisis urbana, la narrativa del Modelo Barcelona constituyó como elemento principal el problema de la seguridad urbana. Así, el Modelo Barcelona se legitimó a partir de una retórica 'criminalizadora' de la vida urbana, que tiene además respaldo en la tradición del urbanismo culturalista y su frecuente concepción de la ciudad como necrópolis (Merrifield, 2002). Esta situación se evidencia tanto en Barcelona como en Bogotá, con la creación de un imaginario de crimen, violencia y deterioro de la vida urbana. Además, el urbanismo barcelonés incorporó la idea de seguridad ciudadana como componente fundamental de la política urbana, dándole a la misma la categoría de derecho ciudadano (Borja, 2005; Borja y Castells, 1997). Ello se refleja no solamente en la retórica de su narrativa (Balibrea, 2004; Borja y Castells, 1997; Fiori Arantes, 2000; Marshall, 2004; McNeill, 1999), sino también en la intervención sobre el espacio público, restringiendo actividades consideradas no estéticas para la 'imagen de la ciudad', así como el reforzamiento de la policía y la masificación de los dispositivos de vigilancia en los espacios públicos (Saltzman, 2008).

Por otro lado, y en desarrollo del segundo elemento planteado, la gestión urbana, Barcelona es ampliamente reconocida como una ciudad global, no solamente por su carácter cosmopolita y la presencia de funciones que la definen como tal, sino también por la implementación de agresivas políticas de inserción en la globalización económica. Por esta razón, diversos autores reconocen la ciudad como uno de los ejemplos paradigmáticos de la gobernancia más allá del Estado, del nuevo localismo y del empresarialismo de Estado local (Blakeley, 2010), tres calificativos que resumen no solamente la tendencia, en términos de política urbana, del modelo neoliberal, sino también la orientación del Modelo Barcelona. En ese contexto la "Planeación estratégica" constituye la principal herramienta, y Barcelona no solamente la implementó, sino que también, a través de su ejemplo, la extendió por todo el mundo, especialmente por América Latina.

La Planeación estratégica parte del supuesto de que las ciudades se desenvuelven hoy en una economía cada vez más globalizada y en medio de una intensa competencia territorial; pero también de que están sometidas a un intenso proceso de tercerización, jalonado especialmente por la información y por extensión los servicios financieros, el consumo y el turismo. Bajo este supuesto, entonces, se construye un discurso orien- 
tado a administrar la ciudad en función al desarrollo de las condiciones que permitan este ideal de ciudad exitosa en un contexto global, en el que se privilegian las actividades terciarias, añadiendo luego un largo listado de virtudes como el desarrollo sostenible, la justicia social, la reivindicación de las minorías, la exaltación de la multiculturalidad, la promoción de la democracia, etcétera (Borja y Castells, 1997; Steinberg, 2005).

En síntesis, se podría señalar que el Modelo Barcelona fusiona dos intereses: aquellos del movimiento posmoderno, que promocionan una cosificación de la cultura, del espacio público, de una 'nueva ciudadanía', de la democracia participativa y de la forma urbana de la ciudad clásica. Y en segundo lugar, los intereses del capitalismo posfordista, incluyendo la incorporación de las manifestaciones culturales como mercancías, la liberalización plena del mundo económico, incluida la liberalización del mercado inmobiliario y la cesión de su control al sector privado.

\section{El "milagro bogotano" y la implementación del Modelo Barcelona: la normativa urbanística "comunicacional"}

Examinados los componentes fundamentales de la planificación comunicacional y su extensión en el Modelo Barcelona, pasamos ahora a examinar la política urbana reciente de Bogotá y su conexión con dichas ideas. Este examen se desarrollará a partir de tres documentos base de la planificación contemporánea de Bogotá: el Acuerdo 6 de 1990, el Plan Estratégico para Bogotá 2000 y el Plan de Ordenamiento Territorial (2000), pero también otros documentos que ilustran la ideología dominante en el urbanismo contemporáneo bogotano.

Empezando con el Acuerdo 6 de 1990, es pertinente señalar que este surge como reacción a la Ley 09 o de Reforma Urbana (1989). Con él se desmontaron no solo gran parte de las reglamentaciones de la Ley 09 con las que se pretendía controlar las distorsiones provocadas por la liberalización del mercado inmobiliario, sino que también se flexibilizó la normativa referida a la urbanización, la cual terminaría excluyendo a la administración distrital de gran parte del proceso de otorgamiento de licencias de construcción. El Acuerdo 6, además, sienta las bases de la normativa urbana de la ciudad en la década de los noventa, cuando la mayor parte de sus temáticas fueron sujeto de reglamentación detallada y constituyó la base para el Plan de Ordenamiento Territorial (en adelante POT), reglamentado en el 2000 y modificado en el 2003 por el Decreto 469 de 2003. Ambas reglamentaciones constituyen, en gran medida, una operacionalización del Acuerdo 6. Examinaremos, entonces, los lineamientos generales de estas tres normas, en el propósito de identificar en ellas la materialización de la utopía comunicacional, objetivo central de este texto.

En primera medida, el Acuerdo concentró su acción en los planes zonales. Contrario a los proyectos totalizantes y comprehensivos de la planificación moderna (el Plan Piloto por ejemplo), la planificación contemporánea se concentró en la acción a nivel local, donde los problemas urbanísticos se resolvían en el nivel de unidades intraurbanas. En los planes zonales, entonces, se detallarían las reglamentaciones de la estructura urbana, incluyendo el diagnóstico de las necesidades, las estrategias a seguir y el programa de inversiones. Sin embargo, los planes zonales solo serían definidos en el POT (2000); los estudios se iniciaron en el 2002, y el primer plan (Usme) fue reglamentado en el 2007. Al 2012 solo se han aprobado tres planes zonales (Centro, Usme y Norte), lo que significa simplemente que en veinte años la ciudad ha dejado el proceso de urbanización en manos de agentes privados, sin una dirección estatal clara.

A lo anterior se añade que la planificación urbana fue diluida en el Plan de Desarrollo, pleno de generalidades, aplazando la reglamentación local detallada, que además se dispersó en una miríada de proyectos con escasa articulación entre ellos (Salazar, 2007). El Plan, por su parte, corresponde a períodos de gobierno y termina desarticulado del Plan de Ordenamiento Territorial que, a su vez, se implementa de manera lenta y solo proyecta al desarrollo urbano a un lapso de 10 años, período en el cual rara vez se ejecutan las políticas definidas en él. 
Es evidente, por otro lado, que con el Acuerdo 6 se renuncia a la planeación física de la ciudad a través de un modelo prediseñado. Por el contrario, por un lado, es la normativa y no el plan la que se constituye en instrumento para controlar la urbanización; y en segundo lugar, el gobierno urbano descarta la intervención directa en la ciudad, restringiendo su acción a limitar los impactos ambientales, físicos y sociales de la urbanización, impulsada por los agentes privados, tal como señala el artículo 60 titulado "El control de los impactos como motivo determinante de las reglamentaciones urbanísticas" (Concejo Municipal de Bogotá, 1990).

De otra parte, y en consonancia con los discursos dominantes de la planificación comunicacional, el espacio público es sujeto de una detallada reglamentación (artículo 70), completado y extendido al resto del país con el Decreto 1504 de 1998 en el que se otorga al espacio público el rol de "...elemento articulador y estructurante fundamental del espacio en la ciudad, así como el regulador de la condiciones ambientales de la misma, y por lo tanto se constituye en uno de los principales elementos estructurales de los Planes de Ordenamiento Territorial" (Presidencia de la República, 1998). Así, el espacio público se erige como elemento central de la planificación urbana y el mismo decreto también incluirá que su administración, mantenimiento y aprovechamiento económico podrán ser asignados al sector privado: no solo una desnaturalización clara del discurso posmoderno sobre la naturaleza del espacio público, sino también un ejemplo de la tendencia que tomaría luego la relación público-privada, con la entrega de los bienes colectivos a agentes privados (estadios, coliseos, vías, parques, reservas naturales, entre otros).

Finalmente, el Acuerdo 6 otorga un amplio peso a las medidas de orden ambiental que se desarrollarán con mayor detalle en la Ley 388 de 1987 y conduce a un POT organizado principalmente en torno a consideraciones ambientales, en particular la idea de estructura ecológica principal concebida como 'elemento primario' del modelo de ciudad propuesto (Concejo Municipal de Bogotá, 1990). Estas inquietudes ambientales evidentemente no detuvieron el avance de los constructores sobre ecosistemas frágiles, aunque permitió la articulación de una 'conciencia ambiental' a una 'conciencia ciudadana', en una estrategia cultural que tuvo bastante éxito en los años noventa para lo que podría llamarse una 'domesticación' de una sociedad urbana bastante agitada a finales de la década de los ochenta. Esta preocupación está igualmente acompañada por otra 'narrativa' contemporánea de gran éxito: la patrimonialización, no solo de los elementos arquitecturales, sino también del capital cultural y natural de la ciudad. En ese sentido, la ciudad desarrolló una amplia normativa, incluyendo el patrimonio como elemento estructurante del POT y, a partir de él, la implementación de un amplio y ambicioso proyecto de renovación urbana que incluye por supuesto el centro de la ciudad, pero también otros sectores que se consideran vitales para la nueva economía globalizada y de servicios de la ciudad.

La reglamentación urbana posterior al Acuerdo 6, en particular el Decreto 619 de 2000 por el cual se adoptó el POT y el Decreto 469 de 2003 que constituye su revisión ${ }^{7}$, reafirmaron las tendencias descritas, pero también añadieron nuevos elementos. Un primer asunto destacable del POT es la idea de definir un 'modelo regional sostenible', propósito que se articula tanto con el peso creciente que adquieren las consideraciones ambientales en las nuevas ideas de la planificación, como el interés por reafirmar unos procesos de competitividad territorial. Tanto la sostenibilidad y sus derivados (la acción ambientalmente responsable y la protección de ecosistemas estratégicos por ejemplo), como la dimensión regional, se encuentran claramente inscritos en el discurso de la gobernanza neoliberal.

En el caso de la sostenibilidad, en la literatura es evidente que la potenciación de un capital ambiental está estrechamente ligado a los indicadores de calidad de vida urbana y estos son considerados determinantes en las decisiones de localización de capital, en conjunto con la atractividad de los espacios

\footnotetext{
7 Una segunda revisión del POT, elaborada en el 2009, fue rechazada por la autoridad ambiental. Dicha revisión es, entonces, aún incompleta y no será considerada aquí.
} 
urbanos para los inversores, pero también para las elites administrativas encargadas de gestionar el accionar de los capitales trasnacionales en las economías urbanas altamente tercerizadas. Al respecto, Gunder anota que "la competitividad global, el desarrollo sostenible y el diseño urbano apropiado [que incluye el acceso a parques y otros equipamientos 'naturales'] han facilitado la atracción del talento a las ciudades clasificadas como ciudades mundiales" (2010). Esta 'marketization de las ecologías públicas urbanas' (Heynen y Robbins, 2005) no se limitó, empero, a la 'verdificación' de la ciudad; también incluyó una reinstitucionalización de la explotación de los recursos de agua, suelos y aire, así como la inclusión del 'valor ecológico' como componente importante de la valorización de los productos inmobiliarios.

Un segundo componente, propio de los discursos de la globalización de los noventa, corresponde a la competitividad territorial. Esta tendría su mayor desarrollo en el objetivo cuatro del plan, referido al propósito de 'aprovechar las ventajas comparativas' del territorio para 'lograr una mayor competitividad' (Concejo Municipal de Bogotá, 2000b). La competitividad es, además, un concepto recurrente en todo el programa del POT, asociado frecuentemente con la productividad y evidentemente con el desempeño de la Región-Bogotá ${ }^{8}$, respecto a las otras regiones del país. El discurso de la competitividad promueve, entonces, el posicionamiento de Bogotá frente a las demás regiones, pero también en un contexto latinoamericano.

El documento guía del POT, por su parte, insiste en la competitividad en múltiples escalas, pero también en una 'competitividad sistémica', que se puede resumir en tres frentes de acción: primero, el posicionamiento internacional en torno a las Ilamadas 'vocaciones productivas', que refieren esencialmente a la industria de exportación y el sector minero (gravas, arenas, calizas y, en general, materiales de construcción). En segundo lugar la infraestructura, en la que

\footnotetext{
8 Que geográficamente es poco clara, pues en ocasiones refiere a lo que podría calificarse como 'área metropolitana', pero frecuentemente se extiende a todo el departamento de Cundinamarca.
}

juegan un rol central las telecomunicaciones, la inversión en los sectores de trasporte terrestre (vías interregionales y equipamiento de transporte) y el aeropuerto internacional. En tercer lugar el capital humano, considerado fundamental en todas las narrativas de la 'sociedad de la información' y que se expresa en la intencionalidad del POT en impulsar la educación superior, científica y tecnológica, para hacer de Bogotá una 'capital educativa de la región andina y del Caribe' (p. 38).

Estos elementos provenían, en su mayor parte, del Plan Estratégico para Bogotá 2000, un proyecto comenzado hacia 1994 y terminado en 1997. Esta propuesta, impulsada por la Cámara de Comercio de Bogotá y coordinada y financiada por las Naciones Unidas, partía del reconocimiento del éxito de la empresa privada en la implementación de planes estratégicos como respuesta a la crisis de los años ochenta, y su reproducción para la administración de las ciudades. El plan estratégico fue el resultado de un proceso de consulta dominada por las organizaciones gremiales e instituciones gubernamentales ${ }^{9}, y$ concluyó, a nombre de todos los ciudadanos, que la ciudad deseada y posible se correspondía con una 'metrópoli latinoamericana', competitiva en los mercados globales, eficientemente administrada, descentralizada, respetuosa del ambiente y promotora del 'orgullo ciudadano' (Alcaldía Mayor de Bogotá, 1997; El Tiempo, 1994), muy cercano al ideal propuesto por los teóricos del Modelo Barcelona.

La realización de este ideal de ciudad competitiva exigía, entonces, la concentración del gobierno urbano en unas acciones precisas que fueron planteadas en los decretos 619 y 469 . Estas fueron, con cierta

\footnotetext{
9 El documento resultado (Alcaldía Mayor de Bogotá, 1997) destaca el alcance participativo listando 37 organizaciones en el Consejo directivo y resaltando la amplia participación de la sociedad civil (p. 8). Sin embargo, el Consejo es ampliamente dominado por los gremios $(48 \%)$ y entidades gubernamentales $(22 \%)$; y los que no aparecen en esta categoría, frecuentemente son fundaciones que corresponden a intereses privados, vinculadas con el sector financiero (Fundación social, p. ej.) o con intereses gremiales (Sociedad de agricultores, Sociedad de arquitectos, p. ej.).
} 
secuencia de prioridades, el énfasis sobre la seguridad, la participación ciudadana, la planeación física y la política fiscal.

\section{Seguridad}

Aunque el tema de seguridad ciudadana había sido siempre una preocupación central de la gestión urbana en Bogotá, la retórica de seguridad se hizo cada vez más prioritaria en los ochenta, hasta generar, a comienzos de la década de los noventa, un imaginario colectivo de terror urbano, que estuvo acompañado de un período particularmente violento debido a la acción de los carteles de la droga y su enfrentamiento con el gobierno.

Así se produjo, entonces, una imagen apocalíptica de la ciudad ilustrada por Martin et al. (2004), quienes señalan que "Bogotá se había transformado en la típica ciudad 'subdesarrollada', con agudos problemas de pobreza, marginación y desigualdad, a los cuales no demoraron en sumarse, a partir de los años ochenta, graves problemas de inseguridad y terror". Esta interpretación, empero, no solo corresponde al deterioro de los indicadores de seguridad ciudadana, que estuvieron estrechamente ligados a la guerra contra el narcotráfico, sino también a los discursos dominantes en el urbanismo de la época que hacían de la seguridad un componente central de la gobernanza en un contexto de globalización (Borja y Castells, 1997).

La seguridad como eje de gran parte de la política urbana fue así reforzada y comenzó a ser parte central de los planes de gobierno. En ese sentido, el plan del primer período de Mockus establecía que "La Administración actuará en defensa del patrimonio colectivo y por una mejor distribución social de los beneficios económicos y culturales del desarrollo de la ciudad", e inmediatamente añadía que la misma "Ayudará a la gente a aprender a usar bien su ciudad. Dicha gestión se facilita con la autorregulación ciudadana, la regulación de la Administración por parte del ciudadano y una nueva cultura institucional" (Alcaldía Mayor de Bogotá, 1995). Evidentemente, la acción estatal colocaba un énfasis especial a la regulación del comportamiento ciudadano a través de diversos mecanismos, especialmente la 'cultura ciudadana', que tenía como propósito central reglar la vida cotidiana a través del uso intensivo de los medios de comunicación y una pedagogía que frecuentemente se asociaba con la delación y el control mutuo de los ciudadanos, muy común en regímenes totalitarios ${ }^{10}$.

La política de seguridad también incluyó acciones más específicas. Una de ellas fue sobre el espacio público en la consideración, muy 'jacobsiana' por cierto, de que una acción directa sobre el espacio físico conduce a modificar las condiciones de seguridad. En esa idea, la política de seguridad ciudadana se articuló a la de espacio público, haciendo de la recuperación del mismo y de la modificación de los elementos arquitecturales, una herramienta de control social y de autorregulación. Esta posición fue claramente plasmada por Peñalosa, quien, inspirado en el conocido alcalde conservador de Nueva York, Robert Giuliani, afirmaba que había una alta correlación entre espacio público y criminalidad (Peñalosa 2002) Este argumento, central en el Plan de Desarrollo 1998-2001, sería continuado en los gobiernos posteriores, particularmente en el segundo gobierno de Mockus (2000-2003).

En resumen, la idea de seguridad ciudadana ha sido un componente central de la gobernanza de la ciudad y también un instrumento excelente de legitimación de la narrativa urbanística contemporánea. La retórica sobre el control a la violencia no solo ha justificado un fortalecimiento de los aparatos policiales, en sintonía con la política de seguridad a nivel nacional, sino que también ha tenido proyección a la gestión y acción sobre

\footnotetext{
10 En el 2003, y en el contexto de la guerra contra el terrorismo y el reavivamiento del conflicto armado en Colombia, Mockus lanzó en Bogotá la Ilamada campaña de la Croactividad en la que se pedía a la ciudadanía la delación como una acción de corresponsabilidad en el combate al crimen. Aunque de amplia aceptación, especialmente entre los gremios, la campaña también fue criticada, especialmente por sus derivaciones frente al conflicto armado y la toma de posición de la ciudadanía. Al respecto, Useche (2004) concluye que "El Alcalde [Mockus], en cambio, no ha podido deslindar su proyecto de resistencia civil de los proyectos policiales de seguridad ciudadana y de su tentación de croactivizar a los ciudadanos; situación en la que observa una moralización no muy distante de las utilizadas para la dominación política y religiosa" (2004: 185).
} 
el ambiente construido y en particular sobre el espacio público.

\section{Participación ciudadana}

Un segundo componente de la política urbana reciente de la ciudad fue la participación ciudadana, considerada como un desarrollo necesario en el contexto del empoderamiento de la sociedad civil y realización de la democracia participativa, en oposición a la considerada decadente democracia representativa (ver p. ej. Fundación Corona, 2003).

Sin embargo, es necesario distinguir entre participación comunitaria y participación ciudadana y más específicamente participación en la planeación, que fue lo implementado por el gobierno urbano de Bogotá después de 1990. La participación comunitaria había sido una constante en el desarrollo urbano al menos desde los años cincuenta, cuando la rápida urbanización y la incapacidad del Estado para proveer viviendas y servicios, condujo a variadas formas de autoorganización a través de las cuales los vecinos se procuraban diversos servicios. Progresivamente estas formas de organización fueron apoyadas por el Estado que las utilizó para canalizar las inversiones, pero también para controlar la población y asociar los movimientos comunitarios a las organizaciones políticas, situación bastante conocida en los años cincuenta con las Juntas de acción comunal.

La participación ciudadana, por el contrario, es inducida directamente por el Estado y se fue convirtiendo, desde los años ochenta, en un elemento central de la gobernanza urbana. Esta condición se reflejó en la normatividad urbana, en particular después que la Constitución de 1991 la estableció como un requerimiento esencial. Luego, con el Acuerdo 12 de 1994, que reglamentó el Plan de desarrollo de la ciudad, se creó Consejo Territorial de Planeación, organismo compuesto por 22 miembros que, aunque de origen diverso, fueron elegidos por el Alcalde mayor y nominados por representaciones de los gremios y de las ONG.

El esquema de participación fue sustancialmente modificado en el 2000 con el Acuerdo 13, a través del cual se reglamentaba el diseño de los planes de desarrollo local, trasladando a la escala local la gestión urbana, un poco en contravía a lo planteado en el POT respecto a una escala de acción metropolitana. El objetivo de este cambio era, por otra parte, fortalecer la participación ciudadana, en la idea de democracia participativa, más difícil de desarrollar a una escala mayor. Así, el Acuerdo 13 creó los Consejos de Planeación Local, encargados de identificar las necesidades de la localidad y debatir y darle seguimiento al Plan de Desarrollo Local, propuesto por las alcaldías menores (Concejo Municipal de Bogotá, 2000a). La implementación de este último acuerdo condujo a un proceso muy activo de participación comunitaria, especialmente en la segunda administración de Mockus (20012003), en la que las localidades elaboraron los planes de desarrollo de su sector a partir de los Consejos Locales de Planeación.

Los resultados de estos ejercicios han sido calificados generalmente como positivos en la medida en que son reconocidos como un paso hacia una mayor democratización de la gestión urbana (Duque Franco, 2008; Fundación Corona, 2003; Velásquez Gavilanes, 2003). Sin embargo, también se formulan críticas, especialmente las relacionadas con la fragmentación escalar de la planificación, esto es, el énfasis en los planes micro, mientras los grandes proyectos y el futuro metropolitano era definido desde arriba; situación más compleja, aun cuando se agrega otra crítica y es que a pesar de la autonomía local, los planes de desarrollo de las localidades estaban condicionados al Plan de Desarrollo Distrital, lo que limitaba el margen de acción de los Consejos locales (Duque Franco, 2008).

A la fragmentación escalar se añade también la fragmentación de los intereses comunitarios y, en general, de los ciudadanos. Los Consejos de Planeación Local se diseñaron con la participación de una panoplia heterogénea de representantes, cada uno con prioridades particulares y representando asociaciones constituidas en función de intereses diversos, lo cual necesariamente condujo a una 'pérdida de visión estratégica de la intervención pública' y competencia entre los diferentes grupos para captar los recursos (Fundación Corona, 2003).

Así, la planificación participativa no condujo a un cambio sustantivo sobre el control 
ciudadano o gubernamental de la urbanización. Por el contrario, la política urbana no se desvió de los discursos de globalización y competitividad, cuyas directrices ya habían sido diseñadas especialmente por los gremios y los políticos ligados al proyecto neoliberal. La participación no era, entonces, solamente un resultado de la insatisfacción ciudadana con el sistema político, como lo plantea Velásquez y González (2003), sino parte de la necesaria transición ideológica hacia la gobernanza urbana neoliberal; situación que no podía ser distinta, dado que la participación ciudadana estaba controlada e impulsada por gremios, fundaciones y ONGs patrocinadas por los primeros ${ }^{11}$.

\section{La planeación física}

Aunque la nueva narrativa planificadora posmoderna se basaba en la descalificación del zoning moderno y renunciaba a los grandes planes urbanísticos, para centrarse en la acción micro y local, es claro que la reflexión sobre el futuro de la ciudad requería la consideración de grandes líneas de intervención física. Así, más que desaparecer, como lo plantean algunos (Cortés, 2007; Pradilla Cobos, 2009), la planeación física cambió de discurso, objetivo y escala de acción.

Un componente central del POT, en ese sentido, son las piezas urbanas, categoría muy correspondiente con la planificación estratégica en la idea de desarrollar una 'operación' cuasi militar para intervenir la ciudad. EI POT definió, en consecuencia, seis grandes áreas (Centro metropolitano, tejidos residenciales norte y sur; y periferias norte, sur y occidental), sobre las cuales se desarrollarían 'operaciones estratégicas' que buscaban intervenirlas y repotenciarlas según sus ventajas de localización.

\footnotetext{
11 Velásquez y González ilustran el protagonismo importante de la Cámara de Comercio, la Fundación Corona, la Andi y Fenalco en los procesos de planeación participativa (2003); e igualmente las estadísticas de participación para los Consejos de Planeación Local evidencian el dominio de ONGs de todos los tipos, así como de organizaciones gremiales (Fundación Corona 2003). Frente a esa situación, es claro que la Planeación participativa tuvo poca independencia frente al poder económico y por tanto al poder político.
}

Estas estrategias estaban estrechamente ligadas a la figura de los macroproyectos urbanos, ya formulada en el Plan de Desarrollo 1994-1998 y con la que se promovía la construcción de grandes complejos de vivienda o empresariales, capaces de orientar el crecimiento de la ciudad y concebidos en una estrecha cooperación del sector público con el sector privado (DNP, 1995). Esta fue, además, una propuesta generalizada en América Latina y que soporta hoy la construcción de grandes proyectos del capital inmobiliario privado, con apoyos diversos de los gobiernos urbanos (Pradilla Cobos, 2009).

Como resultado material de los planes estratégicos, el POT y su revisión establecieron ocho operaciones, resaltando El Anillo de Innovación sobre la calle 26 y el aeropuerto, similar a la proposición del plan de LlewelynDavies en 1974, y el plan del macroproyecto del aeropuerto El Dorado-Fontibón, estructurado alrededor de la ampliación de la infraestructura de aeronáutica y bodegaje en la idea de un incremento sustantivo del tráfico aéreo de la ciudad, en un contexto de fuerte competitividad interurbana. También se incluyó el macroproyecto de Nuevo Usme en el suroriente de la ciudad, y que constituye hoy uno de los más grandes programas de vivienda popular (cerca de 6.300 viviendas), además de ser emblemático de la nueva política en la materia.

Un segundo elemento de la planeación física contemporánea lo constituye la política del suelo, reglamentada para todos los municipios del país con la Ley 388 y de la cual Bogotá ha intentado implementar diversos ejercicios. Curiosamente, la política de suelos se basa en un contexto diverso de ideas sobre la ciudad y las relaciones entre tierra, sociedad y urbanización; aunque ligada a los cambios impuestos por la desregulación neoliberal, tanto en términos de reorientación de la fuente de recursos fiscales; como el impulso al sector inmobiliario, convertido en un sector de vanguardia del crecimiento económico en el capitalismo posfordista (Gottdiener \& Hutchison, 2006).

La política de suelos, en todo caso, se ha limitado a la habilitación de nuevas zonas para el desarrollo urbanístico, manteniendo 
la lógica corriente de urbanización de clases medias en el occidente, altas en el norte, y bajas hacia el sur, cada vez más lejos del centro. Es más, la incapacidad del gobierno urbano para hacer inversiones importantes en vivienda popular, ha conducido a la adquisición de tierras en las periferias aisladas, generando el ascenso de los precios y perdiendo la capacidad de regulación de los mismos, tanto en la periferia como en la ciudad central (Maldonado Copello, 2008). Igualmente, el impacto tributario de la política de suelos ha sido poco relevante, pues a pesar de que la reglamentación por plusvalías se generó desde el 2004, a 2006 solo se había captado 24.000 millones (Saldías Barreneche, 2007); en el presupuesto de 2010 se incluyeron 10.882 millones por dicho concepto, apenas un $0,1 \%$ de los ingresos del Distrito.

Contrastando con dicha política de suelos, de alcance esencialmente fiscal, la regulación urbanística y en particular el control a la construcción, se flexibilizó de manera notable. Gran parte de esta nueva normativa se basaba en la idea de la 'función pública del urbanismo', un eufemismo comúnmente utilizado para legitimar la nueva reglamentación, y en particular la Ley 388, expuesta como una revolución social desde todo punto de vista y que establecía 'la función ecológica y social de la propiedad', teniendo como objetivo "proporcionar los fundamentos jurídicos más sólidos y precisos al derecho urbanístico" (Molina Giraldo, 2003), elementos todos que derivaban de la Constitución de 1991.

Pero estas buenas intenciones necesariamente tendrían que corresponderse con una 'interpretación democrática y solidarista' de la ley (Maldonado, 2003), situación que no ha tenido lugar. Por el contrario, la normativa urbanística se gobernó más bien por la idea de la estrecha colaboración público-privada, la cual condujo a legitimar la intervención directa de los agentes privados como regidores de la dinámica constructiva. Uno de los ejemplos más remarcables de lo anterior fue el desmonte de la intervención estatal en todos los factores incidentes en la provisión de vivienda (Maldonado Copello, 2008), incluido los programas de autogestión, regulando únicamente el tamaño mínimo, el cual, invariablemente, es violado por los constructores (ibid.: 48); así como las otras tímidas medidas orientadas a la exigencia de asignar, en el marco de los proyectos formales de vivienda, vivienda de interés prioritaria.

En consecuencia, la aplicación de la Ley 388 significó la pérdida de autonomía de la ciudad en términos de planificación. Luego de la relativa libertad en el planeamiento que resistió incluso la propuesta centralista de Currie, el gobierno urbano cedió progresivamente sus prerrogativas: primero renunció a los grandes planes urbanos, dejando la expansión de la ciudad sujeta a una normativa general que sería implementada por los particulares, y en especial un capital inmobiliario en plena expansión; luego, las autoridades urbanas delegaron las funciones de control y vigilancia sobre la construcción a actores privados, cuya sujeción a los aparatos de control gubernamentales es, por lo menos, ambigua.

En este último caso, y fundiendo los dos elementos de la nueva narrativa, la eficiencia privada en la gestión y las bondades de la cooperación público-privada, el Gobierno Nacional creó la figura del curador urbano, modelado del sistema de notariado, por demás altamente clientelizado desde hace muchos años y utilizado de manera sistemática para el pago de favores políticos. La figura del curador se justificó en la idea de 'descargar' a las oficinas de planeación de la función de otorgar licencias de construcción, para que pudiese dedicarse a los asuntos de proposición, ajuste y evaluación de los procesos de planeación. No sobra señalar que los gremios y en especial Camacol impulsaron la reglamentación de la figura, basados en la legislación española, que además inspira gran parte de la Ley 388 (Angel Bernal, 2004). La reglamentación de las curadurías quedó establecida inicialmente en el Decreto 2150 de 1995 y luego en la Ley 388 de 1997.

A pesar de la amplia jurisprudencia sobre las licencias y el ejercicio de las curadurías, estas han sufrido varios tropiezos. En primer lugar, al ser el otorgamiento de la licencia un acto administrativo, el curador se limita simplemente a la verificación de la correspondencia de las propuestas con la reglamentación urbanística, sin tener la obligación de hacer verificaciones de campo. En segundo lugar, la remuneración del curador se encuentra sujeta a los proyectos sobre los que debe 
conceptuar, por lo que no solamente se transfieren a un particular recursos otrora públicos, sino que el curador entra en un conflicto de intereses, pues tiene un vínculo económico central con los constructores (Herrera Robles 2004). En tercer lugar, los curadores se enfrentan frecuentemente ante la ambigüedad de las normas, teniendo entonces la potestad de interpretarlas, frecuentemente según los intereses de los constructores, que redunda evidentemente en beneficio de los curadores.

Uno de los sectores más modificados por esta flexibilización en la construcción fue la vivienda, y en particular la vivienda popular. Esta pasó de ser la preocupación central de la planificación urbana, a convertirse en un aditamento más en el proyecto de expansión de la actividad inmobiliaria y refugio esporádico de las constructoras frentes a las recurrentes crisis económicas ${ }^{12}$. La incorporación de la vivienda popular en la lógica de la provisión formal y el mercado estuvo acompañada de una descalificación de la producción informal de vivienda, que se consideraba no solo como de bajas calidades urbanísticas, sino también una competidora ilegal de las constructoras formales. Así, de un involucramiento activo de instancias estatales en la provisión de vivienda para familias de bajos ingresos, definidas en el artículo 278 del POT (2000), se pasó a un dominio exclusivo de este último sobre la 'generación' de suelo apto y barato para la ejecución privada de programas habitacionales que compitiesen con la oferta ilegal (Concejo Municipal de Bogotá, 2003) (Artículo 205, 1, 2003). Igualmente, algunas intenciones de superar la fuerte segregación socioespacial a través de la Vivienda de Interés Prioritaria y la Vivienda de Interés Social, desaparecieron en la revisión de 2003. En suma, la política de vivienda de la nueva planificación se redujo

\footnotetext{
12 Evidentemente, la demanda de vivienda en una ciudad con un alto índice de pobreza y desempleo es limitada. A ello se opone un mercado de vivienda muy dinámico, pero entre las clases medias y altas; mercado que se satura relativamente rápido, por lo que en épocas de recesión muchas constructoras avanzan sobre sectores populares, disminuyendo los costos de suelo y de precio final de la vivienda, complementándolo con presión sobre los gobiernos para ofrecer subsidios directos o indirectos a los compradores.
}

a la generación de suelo por el Estado para la actuación privada subsidiada y el impulso a la generación de un mercado de suelo de vivienda popular, para lo que se reglamentó el control a la construcción ilegal, pero especialmente la legalización de la urbanización informal existente, a fin de fortalecer el mercado inmobiliario (ibid.: artículo 109).

Por otro lado, es necesario señalar que la normativa urbanística, en correspondencia con la influencia ejercida por los discursos posmodernos, incorporó plenamente la idea del espacio público como factor central en la sociabilidad urbana y mejor exponente de la calidad de vida. En ese sentido, la retórica de la 'ciudad abandonada' y la 'ciudad invadida' es frecuentemente esgrimida como razón suficiente para acciones sobre el espacio público. Gehl, uno de los teóricos más conocidos y cercano a Enrique Peñalosa, señala que antes del Nuevo Urbanismo "Las aceras habían desaparecido en los centros de la ciudad [moderna y no necesariamente Bogotá] así como las áreas residenciales y el transporte y la vida en sí misma estaban dependiendo cada vez más del automóvil" (Gehl, 2004), argumentación que difícilmente sería sostenible en la Bogotá de comienzos de los noventa donde la tasa de motorización era muy baja, dado el estricto control sobre la importación de automóviles.

Lo anterior no fue óbice para que la normativa del Acuerdo 6, del POT y de su revisión, tuviesen como uno de los ejes de su formulación la 'recuperación de la dimensión de lo público' que resumía el énfasis sobre el control del espacio público y su intervención. Así, se eliminaron las bahías de estacionamiento público (artículo 184); se propuso un amplio proyecto de parques, alamedas, plazas cívicas en todas las escalas; se estableció la obligatoriedad de la cesión del 8\% del área urbanizable de los proyectos, para espacios colectivos (artículo 250); y se prohibieron los cerramientos, medida difícil de implementar en una ciudad en la que desde los años ochenta se habían generalizado en todos los grupos sociales, los conjuntos residenciales cerrados. Los cerramientos fueron revisados en el 2003, autorizándolos para ciertos casos (artículo 243). Igualmente, fue dedicado un capítulo entero del POT (capítulo 10) a la reglamentación detallada del espacio público, 
yendo desde la escala metropolitana (donde el Concejo de Bogotá no tiene jurisdicción) hasta la escala vecinal y en el que se definían numerosos proyectos de senderos, alamedas y parques; gran parte de los cuales fueron posteriormente derogados o reducidos. En esta reglamentación se reguló con especial énfasis el uso de los antejardines y espacios peatonales (artículo 260), aunque evidentemente gran parte de las normativas allí mantenidas han sido inaplicables.

El Decreto 469 de 2003, por su lado, hizo ajustes importantes al capítulo de espacio público del POT. Por una parte incluyó, como objetivo de la política, el estímulo de la acción privada en la gestión y construcción de espacio público; pero también reorganizó, apenas tres años después, el sistema de parques distritales y añadió más responsabilidades a los agentes privados en la habilitación de andenes y alamedas asociados con la infraestructura vial. En general el acuerdo 469 buscó aligerar la pesada carga que imponía el componente de espacio público, quitando, por ejemplo, la obligatoriedad de construcción de andenes arborizados para los bordes de los parques metropolitanos; flexibilizando las condiciones de gestión de los espacios públicos existentes; aligerando las exigencias para los constructores en los equipamientos comunales públicos (artículo 251 del POT); y eliminando controles estrictos, tanto a los cerramientos como al uso mismo de los espacios públicos (artículo 257 del POT, derogado por el Decreto 469).

Para concluir, el peso del ideal de espacio público se trasladó también a la vivienda y en especial a la vivienda popular. En el afán de los nuevos planificadores por incorporar la vivienda popular al mercado del suelo, se atacó la urbanización informal por su escasez de espacios públicos, exigiendo que dicho componente fuera importante en la nueva vivienda social (artículo 288). Para lograrlo, en un contexto de ascenso importante de los precios del suelo y de lento crecimiento de los ingresos, se sacrificaron los espacios privados, disminuyendo el tamaño mínimo del lote a $35 \mathrm{~m}^{2}$ (Decreto 2060 de 2004), es decir un área promedio menor a $7 \mathrm{~m}^{2}$ por persona, una medida que generalmente no se encuentra en los barrios ilegales consolidados ${ }^{13}$.

Finalmente, podemos incluir en este componente de la planeación física, el plan vial del POT. Este partió de un diagnóstico que se centraba en los altos flujos que recibía la ciudad y una malla vial local y zonal juzgada como insuficiente. A ello se añadía un conjunto de centralidades espontáneas insuficientemente articuladas y la necesidad de consolidar la red intermedia de vías; junto a un fortalecimiento de las vías regionales y la expansión de la red hacia el sur y occidente. En materia de transporte público, el POT concluía en que era obsoleto, y además la ciudad y en especial los sectores populares del sur y occidente tenían un bajo nivel de motorización, lo cual justificaba la configuración de un sistema de transporte masivo (SDP, 2000). Así, y contrario a los planes anteriores donde la forma urbana deseada se articulaba alrededor de un plan de vías, el POT elaboró una propuesta simple, centrada en la organización de un sistema integrado de transporte (metro y Transmilenio), corredores preferenciales, una red de rutas en bicicleta y la modificación del sistema viario existente; el resto del plan solo generalizó sobre la articulación del sistema urbano, evocando algunos elementos del sistema de $7 \mathrm{~V}$ propuesto por Le Corbusier (SDP, 2000).

Las nuevas vías propuestas, por otro lado, son prácticamente inexistentes. El Plan vial solo expuso como novedades la avenida Ciudad de Cali, que había sido proyectada desde 1961 con el nombre de Regional Longitudinal. Su construcción se inició en 1997 y finalizó, incompleta en sus dos extremos, en el 2007, luego de siete años de bloqueo en el paso del Juan Amarillo. La otra propuesta correspondía a la avenida Longitudinal de occidente, trazada siguiendo el margen oriental del río Bogotá y planteada en la idea de continuar estimulando la expansión hacia el

\footnotetext{
13 Una investigación sobre 13 barrios de diferente origen mostró que la insatisfacción de los habitantes con la vivienda formal popular alcanzaba el $90 \%$ (frente a $100 \%$ en la vivienda clandestina) y en términos de área por persona el 36\% de los moradores de vivienda formal la señalaban como mala, frente a un $14 \%$ para los habitantes de barrios clandestinos (Tarchópulos Sierra et al. 2003).
} 
occidente, según proyectaba ya el estudio de Llewelyn-Davies (1974) y se consignaba en el Acuerdo 7 de $1979^{14}$. El resto de vías en el POT solo buscaban conectar viejos trazados discontinuos y el mejoramiento de las vías dentro de la ciudad.

Así, lo más representativo en términos de transporte del POT fue el sistema Transmilenio, basado en carriles exclusivos para la circulación de buses articulados, pero siguiendo los trazados e intersecciones de las principales vías de la ciudad (es decir, con las interrupciones de semáforos y sin construir nuevas vías). El sistema tiene también una dimensión morfológica importante, pues se asociaba con importantes infraestructuras de terminales que, se supone, tendrían un impacto notorio en el mejoramiento del espacio público de varios sectores de la ciudad. Ese impacto fue notable en sectores desarrollados en paralelo con la construcción del Transmilenio, como es el caso del Portal de Suba, Portal del Norte y de la calle 80; pero también en otras áreas como Bosa, Tunal y Portal de Usme donde las nuevas infraestructuras fueron implantadas en sectores populares desarrollados desde los años setenta y ochenta. Esta dimensión del espacio público se sostenía en la idea de que el sistema era también una herramienta de 'armonía social y solidaridad interna' (Mockus, cit. por Gilbert y Garcés, 2008); argumento basado en una eventual confluencia social en su uso que, sin embargo, no se ha producido: los datos muestran que solo el $3 \%$ de los usuarios corresponden a las clases altas y $11 \%$ a las clases medias altas (ibid.: 94).

En fin, podríamos concluir que, contrario a los planes anteriores, en el POT el Plan vial no fue protagonista en esta ocasión, quedando reducido a una 'puesta al día' en la conexión de los fragmentos de vías internas y manteniendo, a través de los proyectos de la

\footnotetext{
${ }^{14}$ De las propuestas mayores del POT solo se ha trazado la avenida Ciudad de Cali, de manera discontinua la avenida Longitudinal y, también de manera incompleta, seis de los 14 tramos de Transmilenio. El proyecto de metro fue abandonado y solo recientemente retomado para estudios preliminares de nuevo trazado, igual que el tren de cercanías, que pretendía conectar los municipios aledaños con la ciudad central.
}

avenida Ciudad de Cali, la avenida Longitudinal y el Transmilenio, la tendencia de expansión hacia el occidente. Los impactos de esta política, de otro lado, se expresarían en la morfología, no solo por el reforzamiento de la expansión urbana sobre los corredores del sistema masivo de transporte y hacia el occidente, sino también porque al no proponer y desarrollar proyectos importantes a nivel metropolitano, generó una intensa densificación de la ciudad central.

\section{Política fiscal}

Contrario a la frecuente simplificación del régimen neoliberal como uno centrado en la contracción del Estado y la disminución del gasto público, los análisis más detallados muestran una variedad de estrategias y adaptaciones de los regímenes neoliberales a los contextos locales (Brenner, 2004). En el caso de Bogotá, si bien la ciudad atravesaba una aguda crisis fiscal a comienzos de la década de los noventa, la existencia de un auténtico Estado de bienestar, y la consiguiente asfixia fiscal, era una situación dudosa. Por el contrario, la crisis derivaba más bien de una baja tributación de los diferentes agentes económicos, aunado a la carga del sostenimiento de algunas empresas de servicios públicos que se habían vuelto insolventes. Estos eran los casos, por ejemplo, de la Empresa de Energía Eléctrica de Bogotá que solamente recaudaba el $40 \%$ de su presupuesto, la Empresa de Teléfonos 30\% o la Empresa Distrital de servicios públicos $27 \%$; datos medidos hacia el mes de abril de 1990 y que se complementaban con la denuncia del alcalde entrante de la época respecto a que recibía la ciudad con un déficit del $13,7 \%$ de los ingresos de la administración central para 1990 (El Tiempo, 1990).

Esta situación, junto con los cambios políticos e ideológicos, permitió la construcción de una narrativa de la 'gobernanza responsable' (Gilbert, 2008), basada en la adopción de las recomendaciones de las agencias multilaterales, en especial aquellos relacionados con la descentralización y privatización. En una primera etapa de esta política se elevaron considerablemente los ingresos a través de la reingeniería al impuesto de valorización y un aumento al impuesto predial. En este proceso jugó un papel importante el Estatuto Orgáni- 
co de Bogotá, reglamentado mediante Decreto 1421 de 1993 que, al desarrollar los propósitos descentralizadores de la Constitución de 1991, le confirió a Bogotá un conjunto de instrumentos fiscales que le permitirían transformar completamente el panorama tributario de la ciudad. Efectivamente, en materia fiscal, el estatuto definió el régimen fiscal de la ciudad, reglamentando en la vía ya definida por el Gobierno Nacional respecto a la disminución de los impuestos directos o al capital y aumento de los impuestos indirectos, es decir, sobre los ciudadanos.

Como consecuencia de este cambio, los recursos de la ciudad aumentaron considerablemente, pasando de 131.000 millones en $1990^{15}$ a 2,2 billones en 1998 y 7,8 billones en 2007. Deflactados los valores a precios de 1990 según el Índice de Precios al Consumidor, los ingresos del distrito aumentaron un $647 \%$ entre 1990 y 2010, con una expansión anual promedio del $12 \%$ y un máximo de crecimiento anual del 55\% entre 1993$1994^{16}$.

Pero no fue solamente un aumento de los recursos, sino también una diversificación de las fuentes. Así, por ejemplo, el rubro de trasferencias de la nación, gracias a la descentralización administrativa, creció un $1.258 \%$ entre 1990-2008 (a precios de 1990) y pasó de significar el $10 \%$ del presupuesto, al 23\%; otros impuestos como el predial y la delineación urbana, aunque mantuvieron una participación similar, crecieron $470 \%$ y $725 \%$, respectivamente, en el período. Finalmente, la contribución del sector productivo (rubro de industria, comercio y tableros) mantuvo su participación en alrededor del 25\% del presupuesto total y creció un 501\%.

Estos datos son perfectamente congruentes con la narrativa planificadora neoliberal, sostenida en la necesidad de aumentar la

\footnotetext{
15 Los cálculos siguientes se basan en el presupuesto de la administración central, que para el 2010 constituía el 56\% del presupuesto general del Distrito.

16 Como comparación, nótese que entre 1981 y 1986 la ciudad creció en términos reales sus ingresos solamente un 4,55\% (Alcaldía Mayor de Bogotá 1987). Cálculos propios a partir de los datos de presupuesto de la Secretaría de Hacienda Distrital y el Banco de la República.
}

competitividad urbana, para lo cual se exigían altas inversiones en infraestructura y por consiguiente aumento de los recursos. En el primer aspecto, es entonces ilustrativo como la ciudad pasó de destinar en 1990 el 45\% de sus gastos a funcionamiento, a solo el $16 \%$ en 2008; simultáneamente, la inversión pasó del $40 \%$ al $76 \%$ en el mismo período, lo que permite comprender las altas inversiones en infraestructura, renovación urbana y espacio público desarrolladas en las últimas dos décadas.

Finalmente, es pertinente anotar que la política fiscal tuvo en la urbanización una fuente importante de recursos y en ese sentido el gobierno urbano se vio cada vez más imposibilitado para controlar el desarrollo de la ciudad. Esta política fiscal también disparó los procesos de metropolización al hacer atractivos para los municipios los ingentes recursos generados por los permisos de vivienda y el consumo asociado, pero también porque las políticas en materia predial encarecieron considerablemente el suelo y la vivienda en la ciudad central, desplazando gran parte de la población, pero también la industria y servicios, estimulados por políticas municipales y regionales con considerables exenciones tributarias.

\section{Conclusiones}

En este reporte se ha buscado establecer la relación entre la narrativa comunicacional en planificación, en particular el Modelo Barcelona, con el proceso de planificación de Bogotá en las dos últimas décadas. El examen elaborado no deja dudas sobre el estrecho vínculo entre el 'milagro bogotano', la gobernanza neoliberal y la implementación del Modelo Barcelona.

Un primer componente de dicha relación se encuentra en el énfasis sobre la competitividad territorial y urbana y la definición, en consecuencia, de políticas orientadas a su fortalecimiento, incluyendo no solo la política social, sino también la política económica y de infraestructura. Las correspondencias, en este sentido, con el Modelo Barcelona son claras, especialmente en la idea de una estrecha colaboración público-privada y la transferencia, a través de diferentes mecanismos, 
de las otrora responsabilidades del Estado, al sector privado. El Plan estratégico 2000, cuyos fundamentos ideológicos son centrales a ambos proyectos, aparece así como el más elaborado producto de la cooperación público-privada entendido como un 'contrato social y político' (Marshall, 2004), que garantiza por demás un bajo nivel de conflictividad y un consenso cívico en torno a un proyecto común, que en realidad es una aspiración de las elites, vendido a través de un muy activo 'patriotismo urbano', como lo denuncia Delgado para Barcelona (Delgado, 2007), pero que tuvo su reproducción en Bogotá con la política de cultura ciudadana y el marketing de la ciudad.

Un segundo componente que acerca el Modelo Barcelona a la planificación de Bogotá, es el interés por una democratización radical de la vida urbana. Efectivamente, el urbanismo barcelonés se reconoció en una 'herencia roja', derivada de movimientos de izquierda, con un proyecto progresista para la ciudad. Sin embargo, la Nueva Barcelona no fue ni el Berlín moderno ni la 'Viena Roja', sino más bien una creación tipo Disney basada en el fin de la ideología y liderada por “...socialistas que no creían en el socialismo, y nacionalistas que no creían en la independencia nacional" (Vásquez Montalbán cit. por McNeill, 1999). En el caso de Bogotá, igualmente la nueva política urbana se promovió como el 'Nuevo urbanismo social latinoamericano' y como un proceso radical de transformación de la sociedad, de la mano de las fuerzas más progresistas de la sociedad colombiana (Dalsgaard, 2009). Larisa Pizano hace un buen balance que muestra en gran medida tanto la 'despolitización' del nuevo urbanismo, como la continuidad en las políticas urbanas neoliberales de las últimas administraciones, otorgando a los alcaldes Jaime Castro la transformación normativa y política, a Antanas Mockus la promoción de la cultura ciudadana y a Enrique Peñalosa la transformación física e identitaria de la ciudad. Añade, además, que los dos últimos alcaldes, salidos del Polo Democrático, partido de izquierda, mantienen la misma línea de gestión (Pizano, 2003). Situación no muy distinta al 'régimen urbano' que Marshall identifica para Barcelona, definiéndolo como una coalición duradera, con un importante soporte en intereses que cubren varios grupos de clase, pero que en todo caso resume las aspiraciones de la elite urbana; coalición sobre la que, además, no se logró construir un contraproyecto (2004).

La democratización de la vida urbana, por otra parte, se asociaba estrechamente al espacio público, considerado como una herramienta democratizadora por excelencia. En ese sentido, fueron de primer orden los programas tanto de defensa del espacio público, como de inversiones arquitecturales que buscaban posicionar la ciudad como un espacio de referencia, aunque evidentemente los recursos destinados para el asunto por Barcelona fueron más significativos que los que pudo dedicar el fisco bogotano. En todo caso, en términos de la morfología y el espacio construido, no deja de ser irónico el cómo una filosofía de ciudad que promovía las densidades razonables y era especialmente enemiga de la construcción en altura (ver p. ej. Gehl y Gemzoe, 2002), terminó, especialmente en el caso de Bogotá, promoviendo las altas densidades y la proliferación de altos edificios tanto para usos residenciales (Torres Jardín), como de oficinas. Podría presumirse entonces, que en gran medida la filosofía posmoderna de la ciudad solamente fue una excusa para legitimar las acciones de un grupo interesado en desmontar el modelo keynesiano e imponer un urbanismo desregulado, manteniendo una alta selectividad sobre los principios de la ciudad reivindicados y descartando aquellos incompatibles con el empresarialismo urbano dominante. ${ }^{17}$

En síntesis, podría concluirse que el Modelo Barcelona, y su versión bogotana, se ajustan a la idea de 'neoliberalismos híbridos', donde la ideología de la planificación toma la forma que le corresponde según la

\footnotetext{
${ }^{17} \mathrm{Y}$ en el cual se incluyen planificadores, arquitectos y estudiosos de la ciudad. Como señala Fiori Arantes, actualmente se experimenta una 'singular comedia ideológica' en la que arquitectos y urbanistas, frecuentemente progresistas, se funden con banqueros, promotores y empresarios en la jerga de la 'autenticidad urbana', más correspondientes a un culturalismo de mercado, el cual se torna en pensamiento único sobre las ciudades (Fiori Arantes, 2000). Hall igualmente observa, con particular ironía, como el planificador se confunde cada vez más con su tradicional adversario, el promotor (1996).
} 
lógica económica y cultural de la sociedad contemporánea y en particular del Ilamado capitalismo tardío. En ese sentido, no es extraño entonces que los impactos más notables de la 'nueva planificación' sean sobre el suelo, dejando al precio del mismo como elemento 'ordenador' del espacio urbano, liberado además a las fuerzas del mercado y con escasa injerencia del Estado, que solo interviene tímidamente a través de la captación de impuestos y plusvalías. Es importante también señalar que esta hibridez está estrechamente asociada con la naturaleza cambiante de las ideologías, y en este caso de los discursos de la planificación. Así, la hegemonía de la planificación empresarial, que lleva más de veinte años, comienza a erosionarse lentamente, siendo cada vez más cuestionada y cediendo espacio a nuevos discursos que vienen posicionándose en la literatura internacional de la planificación. Ejemplos de lo anterior son la idea de ciudad justa (Fainstein, 2010), tomada en el más reciente Plan de Desarrollo; o el de regiones metropolitanas (Scott y Storper, 2003), que alimentó gran parte del discurso en los años 2000, aunque subsidiario al discurso de la planificación comunicativa.

\section{Referencias bibliográficas}

ALCALDÍA MAYOR DE BOGOTÁ. Bogotá para todos. Santa Fe de Bogotá: Alcaldía Mayor de Bogotá / Cámara de Comercio de Bogotá, 1987.

ALCALDÍA MAYOR DE BOGOTÁ. Decreto 295 de 1995, por el cual se adopta el Plan de Desarrollo Económico Social y de Obras Públicas para Santa Fe de Bogotá, D.C., 1995 - 1998 - Formar Ciudad. Santa Fe de Bogotá: Alcaldía de Bogotá, 1995.

ALCALDÍA MAYOR DE BOGOTÁ. Bogotá 2000. Plan Estratégico para el Distrito Capital. Santa Fe de Bogotá: Alcaldía Mayor de Bogotá, 1997.

ALLMENDINGER, P. \& TEWDWR-JONES, M. Planning futures: new directions for planning theory. London - New York: Routledge, 2002.

ANGEL BERNAL, M. L. El curador urbano. Medellín: Señal editora, 2004.
BALIBREA, M.P. Urbanism, culture and the pos-industrial city: challenging the "Barcelona Model". In: MARSHALL, T. (editor). Transforming Barcelona. London: Routledge, 2004, p. 91-96.

BEAUREGARD, R.A. The radical break in late twentieth-century urbanization. Area, 2006, Vol. 38, No 2, p. 218-220.

BÉDARD, M. Être géographe par-delà la Modernité, plaidoyer pour un renouveau paradigmatique. Cahiers de Geographie du Quebec, 2000, Vol. 44, No 122, p. 211-227.

BLAKELEY, G. Governing Ourselves: Citizen Participation and Governance in BarceIona and Manchester. International Journal of Urban and Regional Research, 2010, Vol. 34, № 1, p. 130-145.

BOHIGAS, O. Barcelona : arquitectura y ciudad 1980-1992. Barcelona: Editorial Gustavo Gili, 1990.

BOHIGAS, O. Ten points for an urban methodology. In: MARSHALL, T. (editor). Transforming Barcelona. London: Routledge, 2004, p. 91-96.

BORJA, J. La ciudad conquistada. Madrid: Alianza, 2005.

BORJA, J. y CASTELLS, M. Local y global la gestión de las ciudades en la era de la información. Madrid: Taurus, 1997.

BRENNER, N. New state spaces: urban governance and the rescaling of statehood. Oxford - New York: Oxford University Press, 2004.

BRENNER, N. \& THEODORE, N. Neoliberalism and the urban condition. City: analysis of urban trends, culture, theory, policy, action, 2005, Vol. 9, № 1, p. 101-107.

BROMBERG, P. Ingenieros y profetas: Transformaciones dirigidas de comportamientos colectivos. Santa Fe de Bogotá: Instituto de Estudios Urbanos, 2003.

BUCHANAN, P. Monumentos a una civitas clásico-constructivista. En: BOHIGAS, O. (editor). Barcelona : arquitectura y ciudad 
1980-1992. Barcelona: Editorial Gustavo Gili, 1990, p. 21-25.

CAPEL SÁEZ, H. El modelo Barcelona: un examen crítico. Barcelona: Ediciones del Serbal, 2005.

CARPIÉRE, P. La Planification soviétique: Judith Pallot and Denis J.B. Shaw, Planning in the Soviet Union. Annales de Géographie, 1983, Vol. 92, no 514, p. 742-743.

CASTELLS, M. The rise of the network society. Cambridge, MA: Blackwell Publishers, 1996.

CHOAY, F. La Règle et le modèle: sur la théorie de I'architecture et de l'urbanisme. Paris: Seuil, 1996.

CONCEJO MUNICIPAL DE BOGOTÁ Acuerdo 6 de 1990. Por medio del cual se adopta el Estatuto para el Ordenamiento Físico del Distrito Especial de Bogotá, y se dictan otras disposiciones. Santa Fe de Bogotá: Alcaldía Mayor del Distrito Especial de Bogotá, 1990.

\section{CONCEJO MUNICIPAL DE BOGOTÁ} Acuerdo 13 de 2000. Por el cual se reglamenta la participación ciudadana en la elaboración aprobación, ejecución, seguimiento, evaluación y control del Plan de Desarrollo Económico y Social para las diferentes Localidades que conforman el Distrito Capital y se dictan otras disposiciones. Santa Fe de Bogotá: Alcaldía Mayor del Distrito Especial de Bogotá, 2000a.

CONCEJO MUNICIPAL DE BOGOTÁ Decreto 619 de 2000. Por el cual se adopta el Plan de Ordenamiento Territorial para Santa Fe de Bogotá, Distrito Capital. Santa Fe de Bogotá: Alcaldía Mayor del Distrito Especial de Bogotá, 2000 b.

CONCEJO MUNICIPAL DE BOGOTÁ Decreto 469 de 2003. Por el cual se revisa el Plan de Ordenamiento Territorial de Bogotá D.C. Santa Fe de Bogotá: Alcaldía Mayor del Distrito Especial de Bogotá, 2003.

COOKE, P. Modern urban theory in question. Transactions of the Institute of British Geographers, 1990, Vol. 15, No, p. 331-343.
CORTÉS, R. Del urbanismo a la planeación en Bogotá (1900-1990) esquema inicial y materiales para pensar la trama de un relato. Revista Bitácora Urbano Territorial, 2007, Vol. 1, No 11, p. 160-213.

DALSGAARD, A.M. Bogotá cambió. In: CHALLENGES, M.. Cities on Speed \#4. Dinamarca: Kim Christiansen, 2009.

DEAR, M. \& FLUSTY, S. Posmodern urbanism. Annals of the Association of American Geographers, 1998, Vol. 88, № 1, p. 50-72.

DELGADO, M. La ciudad mentirosa : fraude y miseria del "modelo Barcelona". Madrid: Libros de la Catarata, 2007.

DNP, D.N.D.P. Ciudades y ciudadanía, la política urbana del salto social. Santa Fe de Bogotá: Ministerio de Desarrollo, 1995.

DUQUE FRANCO, I. La renovación urbana en Bogotá, entre el modelo de planeamiento global y la dinámica local. Planeamiento urbano en Bogotá 1994-2007. Barcelona: Universidad de Barcelona, 2008.

EL TIEMPO. El nuevo alcalde de Bogotá critica al gobierno de Andrés Pastrana. 'Es difícil el panorama financiero de Bogotá'. Caicedo Ferrer. El Tiempo. Bogotá: 1990. Disponible en Internet: http://www.eltiempo. com/archivo/

EL TIEMPO. Concertar la ciudad que queremos. El Tiempo. Bogotá: 1994. Disponible en Internet: http://www.eltiempo.com/archivo/

FAINSTEIN, S.S. New Directions in Planning Theory. Urban Affairs Review, 2000, Vol. $35, N^{\circ} 4$, p. 451-478.

FAINSTEIN, S.S. The just city. Ithaca: Cornell University Press, 2010.

FIORI ARANTES, O.B. Uma estratégia fatal. A cultura nas novas gestões urbanas. En: FIORI, O.B.; ARANTES, C.; VAINER, B. y MARICATO, E. (editores). A Cidade do pensamento único: desmanchando consensos. Petrópolis: Vozes, 2000, p. 11-74. 
FLEURY, A. Les espaces publics dans les politiques métropolitaines. Réflexions au croisement de trois expériences: de Paris aux quartiers centraux de Berlin et Istanbul. Paris: Tesis de Doctorado Université de Paris 1 Phanteon-Sorbonne, 2008.

FRIEDMANN, J. Planning in the public domain: from knowledge to action. New York: Princeton University Press, 1987.

FRIEDMANN, J. The New Political Economy of Planning: The Rise of Civil Society. In: DOUGLASS, M. \& FRIEDMANN, J. (editors). Cities for citizens: planning and the rise of civil society in a global age. Chichester, England ; New York: J. Wiley, 1998, p. 19-35.

FUNDACIÓN CORONA. La apuesta de los ciudadanos tercer ejercicio de planeación participativa en Bogotá, 2001. Bogotá: Fundación Corona, 2003.

GEHL, J. Bogotá: la nueva vida urbana en una ciudad reconquistada. En: MARTIN, G.; CEBALLOS, M.; ARÉVALO, A. y ARIZA, C. (editores). Bogotá: anatomía de una transformación. Políticas de seguridad ciudadana 1995-2003. Santa Fe de Bogotá: Editorial Pontificia Universidad Javeriana, 2004, p. 131-138.

GEHL, J. y GEMZOE, L. Nuevos espacios urbanos. Barcelona: Gustavo Gili, 2002.

GILBERT, A. Buen gobierno urbano ievidencia de una ciudad modelo? En: GILBERT, A. y GARCÉS, M.T. (editores). Bogotá: progreso, gobernabilidad y pobreza. Santa Fe de Bogotá: Editorial Universidad del Rosario, 2008, p. 22-69.

GILBERT, A. y GARCÉS, M. T. Bogotá: progreso, gobernabilidad y pobreza. Santa Fe de Bogotá: Editorial Universidad del Rosario, 2008.

GOTTDIENER, M. \& HUTCHISON, R. The new urban sociology. Boulder.: Westview Press, 2006.

GUNDER, M. Planning as the ideology of (neoliberal) space. Planning Theory, 2010, Vol. 9, № 4, p. 298-314.
HALL, P. Ciudades del mañana: historia del urbanismo en el siglo XX. Barcelona: Ediciones del Serbal, 1996.

HAMEL, P. La critique postmoderne et le courant communicationnel au sein des théories de la planification: une rencontre difficile. Cahiers de Geographie du Quebec, 1997, Vol. 41, No 114, p. 311-321.

HARRIS, N. Collaborative Planning. From Theoretical Foundations to Practice Forms. In: ALLMENDINGER, P. \& TEWDWR-JONES, M. (editors). Planning futures: new directions for planning theory. London - New York: Routledge, 2002, p. 21-43.

HARVEY, D. From Managerialism to Entrepreneurialism: The Transformation in Urban Governance in Late Capitalism. Geografiska Annaler: Series B, Human Geography, 1989, Vol. 71, No 1, p. 3-17.

HEALEY, P. Planning Through Debate: The Communicative Turn in Planning Theory. In: FAINSTEIN, S.S. \& CAMPBELL, S. (editors). Readings in urban theory. Cambridge: Blackwell Publishers, 1996, p. 234-256.

HEALEY, P. Collaborative Planning in Perspective. Planning Theory, 2003, Vol. 2, No 2, p. 101-123.

HERRERA ROBLES, A. Las curadurías urbanas. Revista de derecho de la Universidad del Norte, 2004, No 22, p. 137-155.

HEYNEN, N. \& ROBBINS, P. The neoliberalization of nature: Governance, privatization, enclosure and valuation. Capitalism Nature Socialism, 2005, Vol. 16, № 1, p. 5-8.

LARSEN, H. G. \& HANSEN, A.L. Gentrification-Gentle or Traumatic? Urban Renewal Policies and Socioeconomic Transformations in Copenhagen. Urban Studies, 2008, Vol. 45, $\mathrm{N}^{\circ} 12$, p. 2429-2448.

MALDONADO COPELLO, M. M. La ley 388 de 1997 en Colombia: algunos puntos de tensión en el proceso de su implementación. ACE: architecture, city and environment, 2008, Vol. 3, No 7, p. 43-66. 
MALDONADO, M. M. Los principios éticos y jurídicos en materia de ordenamiento territorial y gestión del suelo en Colombia. En: MALDONADO, M.M. (editor). Reforma urbana y desarrollo territorial. Santa Fe de Bogotá: Alcaldía Mayor de Bogotá Universidad de los Andes, Federación Nacional de Organizaciones de Vivienda Popular (Fedevivienda), 2003, p. 207-233.

MANNHEIM, K. Idéologie et utopie. Une introduction à la sociologie de la connaissance. Paris: Librairie Marcel Rivière et Cie, 2003 [1929].

MARRIS, P. Planning and Civil Society in the Twenty-first Century: An Introduction. In: DOUGLASS, M. \& FRIEDMANN, J. (editors). Cities for citizens: planning and the rise of civil society in a global age. Chichester - New York: J. Wiley, 1998, p. 9-18.

MARSHALL, T. Transforming Barcelona. London: Routledge, 2004.

MARTIN, G.; CEBALLOS ARÉVALO, M.A. y ARIZA, C. Bogotá: anatomía de una transformación: políticas de seguridad ciudadana 1995-2003. Santa Fe de Bogotá: Editorial Pontificia Universidad Javeriana, 2004.

MCNEILL, D. Urban change and the European left: tales from the new Barcelona. New York: Routledge, 1999.

MERCIER, G. \& MASCOLO, S. La place commerciale et la mythologie de I'urbanisme contemporain. Le témoinage de la rue SaintJoseph à Québec. In: NOPPEN, L.D. (editor). Architecture, forme urbaine et identité collective. Sillery: Éditions du Septentrion, 1995, p. 53-102.

MERRIFIELD, A. Metromarxism : a Marxist tale of the city. New York: Routledge, 2002.

MOLINA GIRALDO, H. Territorio y ordenamiento territorial urbano. En: MALDONADO, M.M. (editor). Reforma urbana y desarrollo territorial. Santa Fe de Bogotá: Alcaldía Mayor de Bogotá - Universidad de los Andes - Federación Nacional de Organizaciones de Vivienda Popular (Fedevivienda), 2003, p. 115-127.
MONTEZUMA, R. Facing the environmental challenge the transformation of Bogotá, Colombia, 1995-2000: Investing in citizenship and urban mobility. Global Urban Development Magazine, 2005, Vol. 1, N N 1, p. 1-10.

PEÑALOSA, E. La Ciudad y la Igualdad. Santa Fe de Bogotá: Porelpaisquequeremos, 2002.

PIZANO, L. Bogotá y el cambio. Percepciones sobre la ciudad y la ciudadanía. Santa Fe de Bogotá: Universidad Nacional de Colombia-Universidad de los Andes, 2003.

PRADILLA COBOS, E. Las políticas y la planeación urbana en el neoliberalismo. En: BRAND, P.C. (editor). La ciudad latinoamericana en el siglo XXI. Globalización, neoliberalismo, planeación. Medellín: Universidad Nacional de Colombia, 2009, p. 287-306.

PRESIDENCIA DE LA REPÚBLICA Decreto 1504 de 1998. Por el cual se reglamenta el manejo del espacio público en los planes de ordenamiento territorial. Santa Fe de Bogotá: Presidencia de la República, 1998.

ROMERO PEÑAS, J.L. Estudio de la mentalidad burguesa. Madrid: Alianza, 1987.

SALAZAR, J. La planeación de Bogotá: un sistema híbrido de desarrollo progresivo. Revista Bitácora Urbano Territorial, 2007, Vol. 1, $N^{\circ} 11$, p. 208-219.

SALDÍAS BARRENECHE, C. El suelo, una fuente de riqueza colectiva. En: PESCEMONTEIRO, B. (editor). El uso del suelo: un gran desafío para Bogotá. Santa Fe de Bogotá: PNUD-Colombia, 2007, p. 55-69.

SALTZMAN, M.E. The Deteriorating Histories in the Public Everyday Space of PostFrancoist Barcelona. Michigan: University of Michigan, 2008.

SANDERCOCK, L. The Death of Modernist Planning: Radical Praxis for a Posmodern Age. In: DOUGLASS, M. \& FRIEDMANN, J. (editors). Cities for citizens : planning and the rise of civil society in a global age. Chichester - New York: J. Wiley, 1998, p. 163-184. 
SCOTT, A.J. \& STORPER, M. Regions, Globalization, Development. Regional Studies, 2003, Vol. 37, No 6-7, p. 579-593.

SDP, S.D.D.P. Documento técnico de soporte. Plan de ordenamiento territorial de Santa Fe de Bogotá D.C. Santa Fe de Bogotá: Alcaldía de Bogotá, 2000.

STEINBERG, F. Strategic urban planning in Latin America: experiences of building and managing the future. Habitat International, 2005, Vol. 29, No 1, p. 69-93.

TARCHÓPULOS SIERRA, D.; CEBALLOS RAMOS, O. L. y URIBE RIVERA, R. H. Calidad de la vivienda dirigida a los sectores de bajos ingresos en Bogotá. Santa Fe de Bogotá: Ceja, 2003.
TAYLOR, N. Urban planning theory since 1945. London - Thousand Oak: SAGE Publications, 1998.

USECHE ALDANA, O. Violencia molecular urbana y crisis de ciudadanía: el caso de la ciudad de Bogotá. En: BALBIN ÁLVAREZ, J.W.C. (editor). Violencias y conflictos urbanos. Un reto para las políticas públicas. Medellín: IPC, 2004, p. 157-189.

VELÁSQUEZ, C. y GONZÁLEZ, E. ¿Qué ha pasado con la participación ciudadana en Colombia? Santa Fe de Bogotá: Fundación Corona, 2003.

VELÁSQUEZ GAVILANES, R. Bogota, políticas públicas de gobierno local. Santa Fe de Bogotá: Centro editorial javeriano (CEJA), 2003. 